\title{
Editorial: Humour in nonsense literature
}

\author{
Agata Hołobut \\ Jagiellonian University, Kraków, Poland \\ agata.holobut@uj.edu.pl
}

\section{Władysław Chłopicki}

Jagiellonian University, Kraków, Poland

w.chlopicki@uj.edu.pl

The present special issue is quite unique. It grew out of a one-off scholarly seminar entitled BLÖÖF: Nonsense in Translation and Beyond, which attracted international scholars to the Institute of English Studies of Kraków's Jagiellonian University on 18 May 2016 - a venue which had earlier yielded the series of studies entitled In Search of (Non)Sense (ChrzanowskaKluczewska \& Szpila 2009). The discussion at the seminar brought everyone to the, perhaps inevitable, conclusion that nonsense is bound to be humorous, and thus nonsense is definitely within the scope of humour studies. "Nonsense expressions easily become humorous ones, as humans often obtain pleasure from linguistic play and are ready to look for alternative paths to produce meaning. Nonsense has been experienced as a form of freedom, especially as a means to free thinking from the conventional bindings of logic and language" (Viana 2014). The interest in literary nonsense is quite long dating back to such grand figures as Dante, Rabelais, Erasmus of Rotterdam, and especially notably to the Anglosphere with its grand figures of Jonathan Swift, Lawrence Sterne, Edward Lear, Lewis Carroll, James Joyce, and Samuel Beckett. At least since the time of Lewis Carroll and the antics of Alice in Wonderland nonsense humour rose to the status of a 'typically English' phenomenon, and the subject of creative nonsense or sense in nonsense has been quite prominent in English-language literary studies, whether of verse or prose.

Also in humour studies the question of nonsense and absurdity looms large. The humorous verges on the creative and the bizarre in desperate search for meaning, perhaps not in disagreement with Merleau-Ponty, who in his essays Sense and Non-Sense (published in 1964) broadly saw sense somewhere between perception and the absolute. The related notion of paradox featured strongly in humor research (cf. Fry 1963), while the category of nonsense jokes having been studied by psychologists and linguists alike, esp. by Ruch (1998), who saw nonsense humour at the end of the spectrum from incongruity-resolution humour and correlated it in his findings with openness to new experience, non-conformism, and youth. Still the phenomenon of nonsense brings along the exasperating awareness that not all nonsense is humorous, although some is, very much like not all irony is humorous, although 
some is; perhaps not even all parody is humorous, and even more dramatically - not all humour is funny, not to mention the uneasy fact that one person's nonsense is another person's sense, the two said persons being likely to have come from different cultural backgrounds. These essentialist questions pose themselves for the initiated and the uninitiated, particularly for the translators who struggle with apparently nonsensical original texts. And although in the present issue the explicitly essentialist questions tend to be avoided by the authors, who rather prefer to look at linguistic and non-linguistic mechanisms involved in triggering nonsense, they do remain in the background for anyone who would dare to claim some of the examples illustrative of nonsense as unfunny.

And examples are very diverse and numerous indeed. Agata Hołobut and Olga Holownia look at eighteen major nonsense verse anthologies published on the British Isles since the 1920s. Focusing on selected peritexts: titles, cover designs, prefaces, and tables of contents, the authors explore the ways these publications have consolidated, defined, refined, and redefined the genre for consecutive generations of child and adult audiences, gradually expanding the venerated Victorian canon and consequently belying Langford Reed's opinion that "apart from one or two ancient Greek writers, the poetry of Nonsense is essentially British and American in its history and development and is, therefore, impossible of translation" (Reed 1925: 17-8). Cover artwork, which visually synthesises the book contents, has arguably co-defined the genre by visually transposing the main logical and aesthetic procedures of literary nonsense.

These are discussed in detail by Elżbieta Chrzanowska-Kluczewska, who reflects upon humorous and multisemiotic aspects of nonsense literature for children. The author lists formal sources of nonsense-creation in language, for instance semantic anomaly, vagueness, indeterminacy, syntactic ill-formedness, or graphological and phonetic experimentation and explains their mechanism on illustrative examples, grouped into three distinct categories: (1) visual poems; (2) multimodal texts combining verbal nonsense with visual illustration, and (3) poems based on phonetic play. Texts under consideration range from Edward Lear and Lewis Carroll's classical pieces, with selected Polish translations, to Langston Hughes, e.e. cummings, or John Agard's verbal experiments, thus demonstrating the expanding boundaries of the genre and its ability to travel abroad, crossing the borders of languages and cultures.

This ability is further substantiated by Björn Sundmark, who discusses five Swedish translations of Lewis Carroll's "Jabberwocky", the quintessence of verbal ingenuity inherent to literary nonsense and artistic challenge inherent to literary translation. This fascinating series of Swedish rewritings calls into question the presumed untranslatability of the original and confirms Carroll's manifest and manifold presence in foreign literary canons.

The following contributions widen the international panorama of literary nonsense, describing its heritage outside the British Isles. In his vibrant discussion of Carl Sandburg's Rootabaga Stories, Michael Heyman draws out subtle distinctions between British and American nonsense traditions, the latter apparently marked by culture-specific themes and strong folk inspiration in its literary technique.

Using Lewis Carroll as a point of reference, Ailor Porat explores the aesthetic and logical experiments of an eminent Israeli poet, Yona Wallach, revealing nonsense mechanisms in her psychedelic poetics. Finally, Sirke Happonen takes the readers on a guided tour of Finnish nonsense, offering critical insights into two poems of Kirsi Kunnas, an acclaimed children's 
author, whose "Herra Pii Poo" appears for the first time in an English translation. These contributions offer an invaluable glimpse into literary nonsense outside the Anglosphere, demonstrating its shared logic and language-specific aesthetic.

All in all it is hoped the present, necessarily limited, review of humour in nonsense literature will inspire some more, international research on the limits of rationality in our perception of the funny.

\section{References}

Chrzanowska-Kluczewska, E. \& Szpila, G. (2009). In Search of (Non)Sense. Newcastle upon Tyne: Cambridge Scholars Publishing.

Fry, W. (1963). Sweet Madness. A Study of Humor. Palo Alto: Pacific Books.

Merleau-Ponty, M. (1964 [1948]). Sense and Non-Sense. Transl. H.L Dreyfus \& P.A. Dreyfus. Evanston, Illinois: Northwestern University Press.

Reed, L. (1925). 'Preface' in L. Reed (ed.), Nonsense Verses - An Anthology, ill. H.M. Bateman. London: Jarrolds, pp. 1-20.

Ruch, W. (1998). The Sense of Humour. Berlin: Mouton de Gruyter.

Viana, A. (2014). 'Nonsense' in S. Attardo (ed.), Encyclopedia of Humor Studies vol. 2, Los Angeles: Sage, p. 543. 